\title{
The Collaborative Case: From Class Assignment to Publication
}

Colleen Sharen

STLHE SAPES

Brescia University College

Mark Feltham

Fanshawe College

Michelle Braecker

Parkwood Hospital

DOI: $10.22329 /$ celt.v10i0.4759

This essay describes an undergraduate research project involving collaboration among two professors and a student. The result, a business case about the student's workplace, was ultimately presented at an academic conference and is now under consideration for publication. We describe the circumstances that led to the project, its outcomes, and our experiences. In addition, we provide guidance to other professors who wish to promote research collaborations with undergraduate students, referring to principles of assignment design as articulated by John Bean (2011) and the National Council of Teachers of English (2016), among others.

Wndergraduate students frequently seek to fields. Even advanced undergraduates, however, often require considerable assistance with the process of learning to write what MacDonald (1994) termed "expert insider prose" (as cited in Bean, 2011, p. xii). Citing MacDonald's term, Bean (2011) encourages teachers to design portals through which students can "enter their field's discourse community, especially learning how disciplinary genres embody disciplinary ways of thinking and making knowledge" (p. xii). As "students cross the threshold from outsider to insider," Bean later states, "they also cross the threshold from superficial learning motivated by grades to deep learning motivated by engagement with questions. Their transformation entails an awakening-even, perhaps, a falling in love" (p. 253).

Such transformative border crossings require considerable efforts in curricular bridge building, as Bean notes in his extended discussion under the heading "Departmental Collaboration to Teach Undergraduate Research" (p. 253). A related approach, however, involves professor-student collaborative authorship. The authors of this essay engaged in just such a collaboration-a business professor (Colleen), her student (Michelle), and an English professor (Mark) together transformed a course assignment into a conference presentation and a publication. By learning about how this collaboration came about, readers of this essay may be inspired to imagine ways to tailor their own strategies for fostering such collaborations with their own students.

\section{The Context}

The collaborative process began in a third-year course in Leadership Development, required for the leadership major offered at Brescia University College, a small liberal arts university in London, Ontario. Like many academic collaborations, this one arose from an informal conversation between Colleen and Michelle. During a class break, they were 
discussing the lack of high-quality teaching materials for leadership development at the organizational level. Michelle, who had previously graduated from community college and was finishing university part time while working full time at a local hospital, mentioned a situation in her workplace that would make a good business case about leadership development. Colleen and Michelle agreed to pursue this opportunity.

After receiving approval from Michelle's employer, Michelle and Colleen set out to obtain the university's approval for Michelle to take an independent-study course based on this project. With Colleen's help, Michelle prepared a course syllabus requiring a literature review, a decision-based case, an instructor's manual, and an essay reflecting on her own writing, leadership development, and research skills. Michelle met with the Dean and received approval for the independent study. Michelle and Colleen planned to have the case and instructor's manual ready for classroom testing in the Leadership Development course the following academic year and to submit the case to the Administrative Sciences Association of Canada annual meeting, a peer-reviewed academic conference.

\section{The Genre: Business Cases}

A case "is a description of an actual situation, commonly involving a decision, a challenge, an opportunity, a problem or an issue faced by a person (or persons) in an organization" (Maufette-Leenders, Erskine, \& Leenders, 2007, p. 5). Business programs often use cases: Bloomberg Businessweek found that many internationally ranked MBA programs use business cases for up to $75 \%$ of classroom instruction (Levy, 2015). Cases focused on a decision allow students to practice decision-making by analyzing individual, organizational, and environmental factors affecting an organization; developing alternative courses of action; and providing a recommended plan for addressing the issue (Andersen \& Schiano, 2014; Erskine, Leenders, \& Mauffette-Leenders, 2003;
Maufette-Leenders et al., 2007; Naumes \& Naumes, 1999; Yin, 1994).

The case genre, then, calls for a variety of skills. First, the authors must have sufficient expertise to deal with the subject matter of the case. As this subject matter arose from an actual problem in Michelle's workplace, this element fell perfectly into place. In terms of the insider expertise required to write genre-specific prose, cases require a broad range of writing skills: authors must consider the audience's perspective and provide both industry context and the information required to make the decision in question.

Additionally, cases require a description of the protagonist and a logical narrative structure. Cases, moreover, have numerous conventions that often diverge from those of other common school and workplace genres - essays, formal reports, and so on. For instance, cases use the past tense, lack a conclusion, and deliberately —indeed, necessarilyomit information. At the same time, the author must provide enough information to allow the reader to analyze the situation and make a recommendation. The author must also structure the narrative so that the reader can apply the relevant concepts, frameworks, and theories.

In addition, the instructor's manual requires that the author analyze the case situation, select an appropriate business concept or theory, and apply that theory to the case. This manual also requires pedagogical knowledge, as it typically includes learning outcomes, suggestions for specific courses in which the case can be used, a brief summary of the theory that the case illustrates, and a series of discussion questions that help readers engage with the case.

\section{The Research and Writing Process}

Even advanced students benefit from expert guidance in grappling with such complex writing requirements. Colleen thus provided Michelle with exemplars of published cases and instructor's manuals; she also suggested several books on case writing (Erskine et al., 2003; Naumes \& Naumes, 1999). In addition, 
Colleen and Michelle met regularly to monitor progress; these meetings also allowed Colleen to provide any required support, including formative feedback. In particular, they discussed interviewing and note-taking techniques to prepare Michelle for the case-writing process. During this process, Michelle also prepared a literature review of the concepts and theories that she planned to use in the analysis of the case. In addition, Colleen and Michelle discussed each of the theories, assessed their appropriateness with respect to the case situation, and identified the information that Michelle would need to gather and include in the case to allow readers to apply the theories. Michelle then evaluated her entire learning process via a reflective essay.

After submission of the final grade, Colleen and Michelle revised the case using the call for cases (2015) from the Administrative Sciences Association of Canada: this call provided an authentic writing context for the case. They then met with Mark for a series of editing workshops, wherein Colleen provided guidance regarding the case genre and all three collaborated on a substantive review of the case and instructor's manual. The case was accepted for presentation at the conference and publication in the conference proceedings in spring 2015. After peer review, Michelle and Colleen further revised and submitted the case and instructor's manual to a publisher, where it is currently under review.

\section{Voices}

Reflections and conclusions about the process varied quite significantly, as the first-person accounts below illustrate.

\section{Michelle}

My writing skills have significantly improved as a result of writing the case and instructor's manual. To write an effective business case, you need to write clearly and pay attention to detail to meet the needs of your audience. A business case needs to lead the reader through the problem, to consider various solutions. It therefore needs a clear structure, with headings and sub-headings to guide the reader. It was helpful to understand that the case and instructor's manual are best written simultaneously to ensure there is sufficient information in the case to answer the questions. My learning continued through the editing process—specifically, how to communicate a thought succinctly using fewer words. It is amazing how a sentence can have the same meaning by cutting the word count in half! Aside from the improvements in my writing skills, my communication skills have developed further in that I know I have to be curious and ask more questions, no matter how insignificant I perceive them to be, especially when I am in a new situation and learning something that is new to me. I realized that actively listening to others broadens your knowledge because you only know what you know. As a mature student, I not only found value in the voices of others, but I also learned that the ability to collaborate with others effectively leads to successful relationships.

\section{Colleen}

Working collaboratively with a highly-motivated student was an enriching and enlightening pedagogical experience. Michelle contributed her expertise and personal experience with the subject matter of the case, I contributed expertise with the case genre and course theory, and Mark contributed expertise with writing and editing. Much of the work happened during in-person writing and editing sessions. These sessions were highly illuminating: each contributor learned a great deal about the other person's area of expertise. Moreover, as the next section discusses, we also learned strategies for reproducing this positive experience with future projects.

\section{Mark}

Although broadly familiar with the business-case genre from prior editing work with Colleen, I am far from expert. I do, however, have extensive experience as an editor and writing teacher, and I brought these skills to our discussions. Interestingly, however, 
during our editing sessions, a lot of my advice was context-dependent in the sense that experienced case writers have their own ways of doing things. I also have almost no knowledge of the subject matter of the case, matter in which Michelle is the expert. I frequently found myself in a three-way conversation with Michelle and Colleen, as I had to adjust my advice based on what Michelle meant when she wrote a particular sentence and on Colleen's expert knowledge of the generic and rhetorical conventions of the case genre.

\section{Design Assignments with Intent: Optimizing Assignments to Promote Opportunities}

The process described above benefitted from highly fortuitous circumstances: the course material and outcomes and Michelle's own background experience and professional life meshed perfectly with the genre of the business case. All of this arose from a chance conversation during a break in class and was implemented as an independent study course, another enabling factor promoting a high level of customization and collaboration. Although such happy conjunctions can arise spontaneously, such moments are probably relatively rare. Collaborative professor-student projects are special situations: every course assignment cannot turn into this kind of a project for every student. World enough and time both are lacking. Despite time and resource constraints, however, there are some ways to design courses and assignments so that such opportunities become more likely.

The right design decisions can optimize course assignments so that even if full-scale collaborations do not occur, the assignments help prepare students for future opportunities in subsequent courses, jobs as research or teaching assistants, senior projects, graduate programs, or whatever other opportunities await the students in a given course. Although strategies for promoting such opportunities will vary with the research methods, generic conventions, and publication opportunities in different fields, there are ways to avoid surrendering to circumstance. Professors seeking to foster such moments can stack the deck.

Careful assignment design is one way to do so. Interested and able students are a necessary but not sufficient condition for collaboration: some vehicle for collaboration must also exist. Such vehicles are the result of design decisions: professors can thus maximize the potential for such collaborative opportunities by engaging in what John Bean (2011) calls "backwards design" (p. 96). This concept plays a significant part in Bean's book-length discussion of how to design assignments that allow students to engage critically and actively with authentic problems; it also provides a compelling model for describing the assignment that gave rise to this entire collaboration. Under the heading "Planning Your Course Backward by Designing the Last Assignment First," Bean observes that when "teachers design [the] last assignment first, they can analyze its level of difficulty, determine the kinds of problems students are apt to encounter, and then design earlier assignments that help students build the skills needed for the final assignment" (p. 96). In terms of the collaboration under discussion here, circumstances presented an opportunity for a custom course designed backwards from a business case.

Professors should thus be alert to the opportunities posed by the professional discourses and genres of their own fields, and they should seek to craft assignments that reach towards potential publication. Of course, not all genres are appropriate for even highly advanced undergraduate students: for example, it is unlikely that even the most advanced bachelor's candidate would co-author a scholarly monograph with a professor. However, an undergraduate might complete an assignment that leads to work as a research assistant, resulting in experience with the production of a monograph and mention in the acknowledgements.

Even when it is not appropriate for a student to create a real-world example of a genre with an eye towards publication, though, professors can carefully introduce students to these genres by anatomizing them, explaining their role within the discourses of their fields, and modelling how they themselves useand create-the genres. Such use of "mentor or 
exemplar texts" is a best practice for writing teaching that promotes the formation of a "mental model of the genre" (National Council of Teachers of English, 2016, What Does This Mean for Teaching section, para. 3). Bean (2011) makes essentially the same point when he notes that "students aiming for expert insider status need to present their research in one of the real genres of their discipline" (p. 256).

Part of the professor's job, then, is to design realistic opportunities that lead to more advanced opportunities later, whether in proximal post-course work or work at the distant end of the curriculum. For example, when publication is not possible, professors can also design assignments and assignment processes that simulate real-world publication genres of interest to the students. Such opportunities may give rise to entries in writing contests, submission to student conferences, student journals, graduate student journals, or even professional journals, depending on the circumstances. As Bean (2011) further notes, such design criteria can span an entire curriculum, in collaboration with other faculty members. "Working together," he states, "departmental faculty can design the curriculum backwards to ensure that the skills and knowledge needed for expert insider prose are taught gradually and sequentially in key courses throughout the major" (p. 260).

Genre exposure via exemplars, check-in meetings, literature reviews, and the various other supportive elements of the course that Colleen and Michelle designed illustrate the principle of scaffolding, a well-known and oft-cited term in teaching and learning closely connected to the concept of backwards design discussed above, as Bean (2011) himself repeatedly indicates. All of the scaffolds noted above, including the choice of exemplars, their level of difficulty, and their generic features will necessarily vary according to the individual courses and disciplines. These basic structural elements, when carefully designed and built into achievable assignments, will increase the chances of productive collaborations, even if these collaborations do not materialize until years later in more advanced courses.

\section{The End Is not the End: Committing to the Process}

When collaborative publications do occur, the end of the course is never the end of the work. As a result, the professor and the student must both be willing to make the necessary time commitments to help the collaboration succeed. In addition, the professor and the student must actually get along with each other: a collaborative project will probably not succeed if the parties cannot work together effectively. The participants must thus be particularly attentive to the interpersonal factors in play during the shift from the conventional professor-student relationship to a relationship in which the professor functions more like a collegial mentor. Beyond these basic interpersonal factors, moreover, both parties need to manage the workload associated with the process: even if they have the time, they must also be able to work productively within the time available. Finally, the student must be able to handle the peer-review process both intellectually and emotionally, especially in terms of engaging with the honest-sometimes brutally honest-comments that often arise when outside eyes appraise his or her work.

\section{Phone a Friend: Bring in Outside Eyes, As Needed}

Certainly, Colleen did not require outside assistance to help Michelle write a business case-as a business professor and author of many such cases, Colleen is already an expert insider. Depending on the project, though, the situation may be different. For example, a psychologist may need to engage a statistician, a biologist may need to engage a biochemist, and a physicist may need to engage a mathematician. Less obvious interdisciplinary collaborations may be particularly interesting: one wonders what as-yetunthought-of projects might involve English professors working with physicists, or anthropologists and mathematicians sitting down to collaborate over coffee. It is also possible that no additional expertise 
will be required, depending on the project in question.

In this case, although Mark's involvement was not strictly necessary, he and Colleen had collaborated on other projects, and she wanted to provide Michelle with an enriched experience that not only included exposure to other forms of disciplinary expertise but also a fresh audience. In this way, his involvement actually modeled interdisciplinary aspects of collaborative authorship and, moreover, introduced Michelle to the idea of an academic community as a network of experts engaged in collegial collaboration. Indeed, as described above, Mark's engagement with the draft case went beyond just copy editing: it resulted in a three-way conversation about how the language of the draft related to its generic requirements and content.

Such conversations are a common-and often joyful-part of writing life. A glance at the acknowledgements section of almost any publication usually reveals the names of various academic friends who have read and commented on drafts of the text. A published text is, after all, meant to be publicmeant to become the nexus of a community of readers. Early exposure to community responses, simulated by formative feedback from a friendly yet critical audience, can introduce the student to such community networks while simultaneously enhancing the project. Indeed, the National Council of Teachers of English (2016) emphasizes the importance of collaboration, along with the larger point that writing

happens in the midst of a web of relationships. Most clearly, the relationship between the writer and the reader can be very specific: writers often have a definite idea who will read their work, not just a generalized notion that their text will be available to the world. Furthermore, particular people surround the writer-other writers, friends, members of a given community-during the process of composing. (Writing is embedded in complex social relationships section, para. 1)
This statement is an extremely helpful guiding curricular principle: by building a web of relationships and careful assignment design, professors can make in-course writing processes more authentic, thus minimizing the writing-in-a-vacuum effect that can accompany course papers for which the only audience is the professor required to grade them.

\section{Conclusion}

A chance conversation between a student and a professor led to this collaboration; this professor happened to have a collaborative relationship with another professor willing to assist during the postcourse writing process. Different characters and different relationships will produce different outcomes. Just because this collaboration arose from this particular matrix of circumstance, however, does not mean that others cannot reproduce its general result. Professors seeking to do so will necessarily operate in their own contexts, shaped by individual preferences, affinities, workloads, ethics, and even institutional policies. Moreover, as Bean (2011) observes, the quest towards expert insider prose involves multiple elements, including "subject matter knowledge, genre knowledge, discourse community knowledge, information literacy, rhetorical knowledge, and writing process knowledge" (p. 254). Although the discussion above touches in various ways on each of these points, readers will know that each one accordions out into a vast file of separate design questions, each with its own sub-questions. Such variable-laden situations do make for complicated problems in curriculum design. Nevertheless, such problems tend in their solving to produce the most rewarding results. The collaboration that began with a chance conversation has thus far produced a successful course assignment, a business case and instructor's manual, a conference presentation, and now this published essay. The case itself is under consideration for publication. By taking the right steps to engineer the right circumstances, others can achieve similar results. 


\section{References}

Andersen, E. \& Schiano, B. (2014). Teaching with cases: A practical guide. Boston, MA: Harvard Business School Publishing.

Bean, J. C. (2011). Engaging ideas: The professor's guide to integrating writing, critical thinking, and active learning in the classroom ( $2^{\text {nd }} \mathrm{ed}$.). San Francisco, CA: Jossey-Bass.

Erskine, J. A., Leenders, M. R., \& MauffetteLeenders, L. A. (2003). Teaching with cases $\left(3^{\text {rd }}\right.$ ed.). London, ON: Richard Ivey School of Business.

Levy, F. (2015, April). Harvard Business School has the market cornered on case studies. Bloomberg Businessweek. VIEW ITEM

MacDonald, S. P. (1994). Professional academic writing in the humanities and social sciences. Carbondale, IL: Southern Illinois University Press.

Mauffette-Leenders, L. A., Erskine, J. A, \& Leenders, M. R. (2007). Learning with cases ( $4^{\text {th }}$ ed.). London, ON: Richard Ivey School of Business.

National Council of Teachers of English. (2016, June 2). Professional knowledge for the teaching of writing. VIEW ITEM

Naumes, W., \& Naumes, M. J. (1999). The art \& craft of case writing. Thousand Oaks, CA: Sage Publications.

Yin, R. K. (1994). Case study research: Design and methods ( $2^{\text {nd }}$ ed.). Thousand Oaks, CA: Sage Publications.

\section{Biographies}

Colleen Sharen is an Associate Professor of Management and Organizational Studies in the School of Leadership and Social Change at Brescia University College.

Mark Feltham is a Professor of English/Communications at Fanshawe College.

Michelle Braecker works at Parkwood Hospital. 


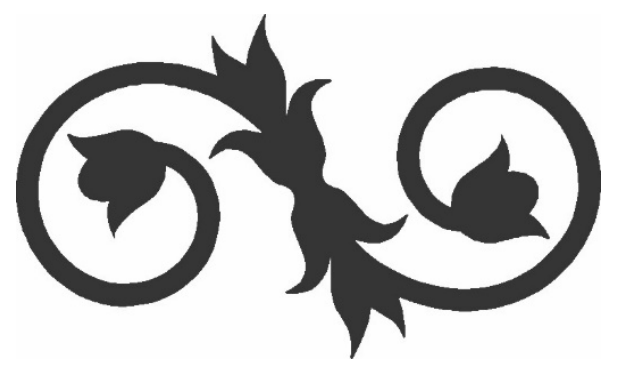

